\title{
PERFORMANCE OF SMALL CAPACITY COMPRESSION IGNITION ENGINE USING JATROPHA BIODIESEL BLENDS
}

\author{
Sagar G Chaudhari ${ }^{1}$, Maulik A Modi ${ }^{2}$, Tushar M Patel ${ }^{3}$, Gaurav P Rathod ${ }^{4}$ \\ ${ }^{1} P G$ Scholar, Mechanical Engineering Department, LDRP-ITR, Gujarat, India \\ ${ }^{2}$ Lecturer, Mechanical Engineering Department, LDRP-ITR, Gujarat, India \\ ${ }^{3}$ Associate Professor, Mechanical Engineering Department, LDRP-ITR, Gujarat, India \\ ${ }^{4}$ Assistant Professor, Mechanical Engineering Department, LDRP-ITR, Gujarat, India
}

\begin{abstract}
Alternative fuels for internal combustion engine are area of research for past few decades because of limited quantity of fossil fuel used today. Biodiesel fuels are one of the candidates of the alternative fuel for compression ignition engine due to many advantages. In this research performance of single cylinder, 4-stroke, water cooled, variable compression ratio diesel engine running using jatropha biodiesel blends (B10 to B50 with increment of 10) is discussed. Nonedible biodiesel blend is chosen to avoid food security related problem in case of edible oil based biodiesel. Engine was run at default set compression ratio of 17.5 and injection pressure of 180 bar. Performance was measured at three different loading condition for each blends used in investigation. It was found that at lower blends performance is similar to that of diesel fuel. Highest thermal efficiency was found for B20 v/v blend which was $26.43 \%$ while other blend B30 shown similar thermal efficiency compare to diesel but was lower than B20. Emission of engine running with biodiesel was almost similar to that of diesel and there was no significant difference observed.
\end{abstract}

Keywords: Alternative Fuels, Nonedible oil Biodiesel, Compression Ignition Engine, Energy Analysis

\section{INTRODUCTION}

Today global energy demand is increasing day by day with rising of population. According to international energy agency estimation, global energy demand is expected to increase $53 \%$ by 2030 . Currently major part of energy demand is fulfilled by fossil fuels in which crude oil account for $33.7 \%$, coal for $30.5 \%$ and natural gas for $24.4 \%$ [1]. Petroleum fuel plays very important role in the development of the industrial growth, transportation, agriculture sector and to meet many other human basic needs [2]. If we talk about transportation sector and many other power application Internal Combustion engine plays irreplaceable role in the society. But mostly IC engine has brake thermal efficiency(BTHE) in the range of $20-40 \%$, it means around $60 \%$ of the energy is got wasted. Also due to use of petroleum fuels IC engine emits harmful gases such as $\mathrm{CO}$, NOx and HC(Hydro Carbon) particles. So it can be said that there will be shortage of fuel in near future and also environment pollution leads to health problems and also global warming problem. So it leads to find alternative energy sources which can eliminate the above stated problems.Some of the alternative fuels are found such as biodiesel, biogas and hydrogen which are renewable energy sources. CNG and LPG are also used now a days but they are supplement energy sources. Biodiesel is one of the best available source to fulfil energy demand and alternative to IC engine fuel which can be used without or with few modifications [2,3]. Biodiesel is renewable and zero polluting fuel as carbon dioxide is reused in carbon cycle by the crops of vegetable oil.
Selection of proper alternative fuel for particular continent is also important because land properties are differ from continent to continent. Currently more than $90 \%$ of the biodiesel is produce from edible oil because of its abundant agricultural production for instance palm oil( South Asia), soybean oil(US), coconut oil( Philippines) and rapeseed oil( Europe) [1]. But if edible oils are used for biodiesel production then there will be food vs fuel controversy and hence it will be better to find biodiesel source from nonedible oil crops. There are many non-edible oil plants are available among which few are the major candidates of biodiesel production. In one research it was found that neem, karanja, rubber, jatropha, mahua are major candidates as they can be grown in diverse socio-economic and environmental conditions and also they are multipurpose plants which founds its applications in medicines, dyes, ornamental, feeds, soil enrichments, afforestation etc [4]. Nabnith panighari et al[5] have analysed the single cylinder diesel engine running with mahua biodiesel blends and they found that B20 fuel has higher thermal efficiency and brake specific fuel consumption (BSFC) compared to other blends and NOx emission is higher for biodiesel compared to diesel. S Sivalakshmi et al.[6] have checked the performance of 4 stroke single cylinder diesel engine fuelled with Neem oil biodiesel and they found that lower blend ratio gives better performance compared to diesel fuel and combustion process is improved with biodiesel. NOx emission was found higher for biodiesel compared to diesel. With higher blend ratio NOx emission tend to increase. Jibanananda jena et al[7] have carried out an research work on the 4-stroke single cylinder diesel engine using karanja 
and palm biodiesel. They found that karanja and palm oil shows higher thermal efficiency than the diesel and energy destruction was found higher for the diesel fuel. Agrawal et al.[8] have checked the performance of the diesel engine using linseed biodiesel as a fuel. They found that 50\% linseed blend gives maximum thermal efficiency and lowest BSFC in this experiment. Smoke emission was higher for B50 blend compare to others (B10, B20 and B30). Ramadhas et al.[9] have investigated the performance and emission characteristics of diesel engine fuelled with rubber seed oil biodiesel. They found that lower blend ratio increases the BTHE and reduces fuel consumption. Emission was found to be reduce with higher biodiesel concentration.

As current research belonging to Indian continent, in India more than 75 non edible crops are found whose fuel characteristics were found similar within the specification of USA, Germany and Europe. Although very few which are studies experimentally such as neem, rubber, rice bran, jatropha curcus etc [10]. Jatropha curcus was also recognized by the government of India and many trials were also done after biodiesel policy implemented in 2009 but due to some financial problems and other reasons it was fail to implement blending of it commercially[11]. But jatropha curcus has potential to be used as biodiesel in India. So in this research work biodiesel made from nonedible oil crop jatropha curcus is used as fuel and performance of its blends was measured and compared with petroleum diesel. Three loading condition were used to check the performance at all kind of loading condition

\section{EXPERIMENTAL SETUP AND METHOD}

\subsection{Experimental Setup}

Test engine setup is shown in the Fig-1. It is single cylinder, 4 stroke, water cooled variable compression ratio(VCR) engine which can be run on petrol and diesel by changing engine head. In this experiment diesel engine head is mounted. Engine output shaft is connected with eddy current dynamometer for measurement of brake power. Fuel and air are supplied to the engine from separate unit of fuel tank and airbox. Engine consists of various sensors such as temperature sensor, load sensor and speed sensor etc for measurements. Calorimeter is also attached after the exhaust line for specific measurement. Water is supplied to engine for cooling and to calorimeter. Flow rate of water can be measure with the help of rota meter and flow can be controlled by valve. Gas Analyser was used for emission measurement. All required notation are mentioned in the Fig-1. Test engine specification is also shown in Table1.

\subsection{Experiment Methodology}

Engine was made to run at manufacturer set value of compression ratio 17.5 and readings for energy analysis were taken for different blends ( B10 to B50 with increment of 10).Engine was made to run for three different loading conditions as low, medium and high for same blends. The measurements were taken after the steady state condition was reached.Though this engine setup has facility to automatic reading measurements at some fixed interval of time with data acquisition system, due to some technical problems readings were measured and noted manually.Load was varied with the help of voltage knob and reading directly indicates values in terms of load in kilogram. Fuel consumption was measured manually by measuring time for fixed amount of fuel consumption ( $10 \mathrm{cc}$ in this case) for different fuels at different loading conditions. From the air box manometer difference was noted every time which is used to calculate mass of air consumption. Mass flow rate of water for engine cooling and for calorimeter was set by valves and values of flow rates were measured from rota meter.

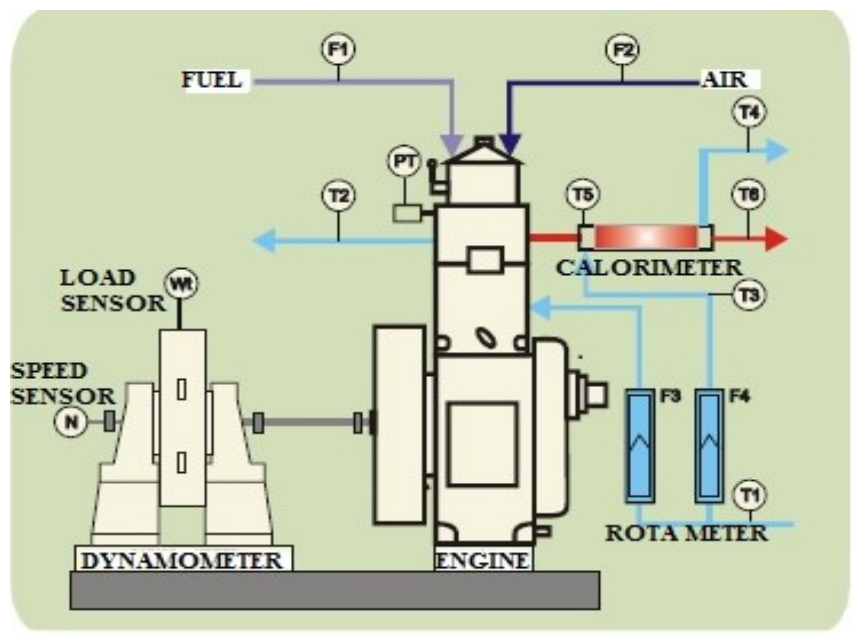

Fig-1. Test Engine Setup[12]

Table 1. Test Engine Specification[12]

\begin{tabular}{|c|c|}
\hline Particular & Specification \\
\hline Engine & $\begin{array}{l}1 \text { cylinder, } 4 \text { stroke, water cooled } \\
\text { engine }\end{array}$ \\
\hline Bore and stroke & $87.5 \mathrm{~mm}$ and $110 \mathrm{~mm}$ \\
\hline Rated power & $3.5 \mathrm{~kW}$ at $1500 \mathrm{rpm}$ \\
\hline Dynamometer & $\begin{array}{l}\text { Eddy current type, water cooled with } \\
\text { load unit }\end{array}$ \\
\hline Air box & $\begin{array}{l}\text { M S Fabricated with orifice meter and } \\
\text { manometer }\end{array}$ \\
\hline Calorimeter & Pipe in pipe type \\
\hline $\begin{array}{l}\text { Temperature } \\
\text { sensor }\end{array}$ & $\begin{array}{l}\text { RTD type PT } 100 \text { and Thermocouple, } \\
\text { type K }\end{array}$ \\
\hline Load sensor & $\begin{array}{l}\text { Load cell, type strain gauge, range } 0 \text { - } \\
50 \mathrm{~kg}\end{array}$ \\
\hline Load indicator & $\begin{array}{l}\text { Digital, range } 0-50 \mathrm{~kg} \text {, supply } 230 \mathrm{~V} \\
\text { AC }\end{array}$ \\
\hline Rota meter & $\begin{array}{l}\text { Engine cooling 40-400 LPH, } \\
\text { Calorimeter } 25-250 \mathrm{LPH}\end{array}$ \\
\hline Fuel tank & $\begin{array}{l}15 \text { litre capacity with fuel metering } \\
\text { pipe of glass }\end{array}$ \\
\hline
\end{tabular}

Temperature readings were taken from the digital indicator. This include various temperature readings such as engine 
cooling water inlet and outlet, calorimeter water inlet and outlet and exhaust gas inlet and outlet temperature in calorimeter. Gas analyzer was used for the measurement of exhaust gases volume fractions. Required Properties of jatropha biodiesel were tested in chemical laboratory. Some tested value is shown in Table2.

Table 2. Fuel Properties Tested for Biodiesel

\begin{tabular}{|l|l|}
\hline Calorific Value & $38074.4 \mathrm{~kJ} / \mathrm{kg}$ \\
\hline Specific Gravity & 0.85 \\
\hline Flash Point & $208^{0} \mathrm{C}$ \\
\hline
\end{tabular}

\section{ENERGY ANALYSIS}

Energy analysis is based on the first law of thermodynamics, which is also known as energy conservation law. For doing energy analyses following assumptions are made[2,4]:

- The engine operates at steady state condition

- The whole instrument including dynamometer is selected as control volume

- The combustion air and exhaust gas each forms ideal gas mixtures

- Potential and kinetic energy effects of the incoming and outgoing fluid streams are ignored

Steps involving the energy Analysis are as shown below:[13]

Fuel energy supplied in unit time is given by the following equation:

$\dot{Q}_{\text {in }}=\dot{m}_{f} \times L C V$

Where $\mathrm{m}_{\mathrm{f}}=$ mass of fuel consume per unit time $(\mathrm{kg} / \mathrm{s})$ and $\mathrm{LCV}$ is lower calorific value of the fuel $(\mathrm{kJ} / \mathrm{kg})$. From above equation energy input to the engine can be found out.

Shaft power or the mechanical brake power of the engine can be calculated as shown below:

$\dot{Q}_{B P}=$ Brak Power of the Engine

$=2 \pi N T / 60,000$

Where $\mathrm{N}$ indicates speed in $\mathrm{rpm}$ and $\mathrm{T}$ indicates torque of engine in $\mathrm{Nm}$.

Heat loss in engine cooling water per unit time is given as following equation:

$\dot{Q}_{C W}=\dot{m}_{c w} \times C_{p w} \times\left(T_{C 2}-T_{C 1}\right)$

Where $\mathrm{T}_{\mathrm{c} 1}, \mathrm{~T}_{\mathrm{c} 2}$ are engine cooling water inlet and outlet temperatures in $\mathrm{K}$ and $\mathrm{C}_{\mathrm{pw}}$ is specific heat of cooling water.

Heat Carried away by exhaust gases can be calculated as shown in equation below:

$\dot{Q}_{e x}=\dot{m}_{e x} \times C_{p e x} \times\left(T_{e x 1}-T_{0}\right)$
Where $\mathrm{T}_{\mathrm{ex} 1}, \mathrm{~T}_{0}$ are exhaust gas inlet and ambient temperature respectively in kelvin and $C_{p e x}$ is the specific heat of exhaust gases.

mass flow rate of exhaust gases can be found by summing up mass flow rates of air and fuel.

$\dot{m}_{e x}=\dot{m}_{a}+\dot{m}_{f}$

Specific heat of exhaust gas can be found by equating energy balance of heat loss by exhaust gas and heat gain by the water in calorimeter.

Heat gain by water in calorimeter $=$ Heat loss by exhaust gases in calorimeter

$\dot{m}_{w c a l} \times C_{p w} \times\left(T_{C 4}-T_{C 3}\right)=m_{e x} \times C_{p e x} \times$

$\left(T_{e x 1}-T_{e x 2}\right)$

Unaccounted energy losses which includes heat loss due to radiation and heat loss to oil and friction power loss etc. sum of these losses can be found out as follow:

$\dot{Q}_{u}=\dot{Q}_{i n}-\left(\dot{Q}_{c w}+\dot{Q}_{e x}+\dot{W}_{s}\right)$

Brake thermal efficiency(BTHE) can be found out as:

$\eta=\frac{\dot{W}_{s}}{\dot{Q}_{\text {in }}} \times 100 \%$

\section{RESULT AND DISCUSSION}

\subsection{Performance}

During experiment engine ran on CR 17.5 and IP 180 bar which was default setting on the engine. Engine was fed with pure diesel and different blends of jatropha biodiesel (B10 to B50) for the purpose of energy analysis. All the necessary measurements were taken for the energy analysis of the engine. Results obtained from this analysis are discussed and represented in the graphs as below:

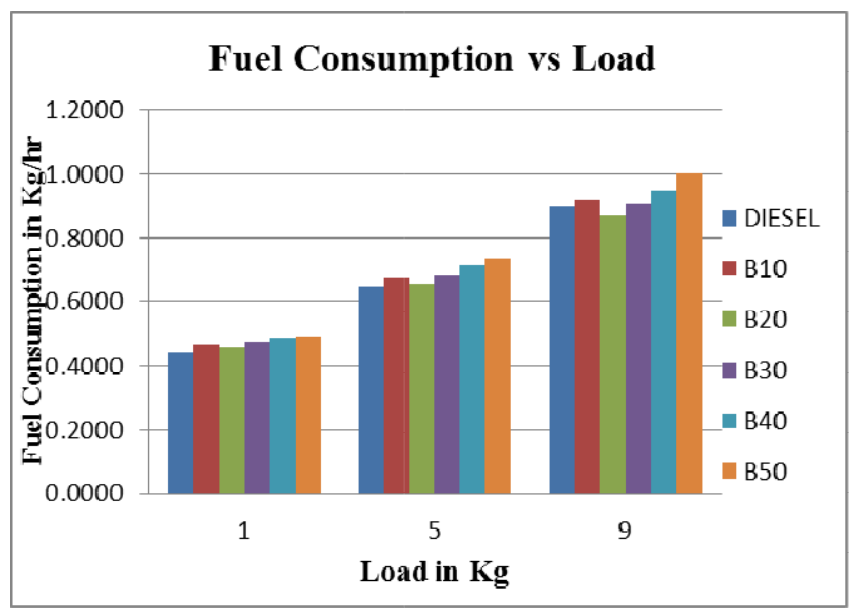

Fig-2. Comparison of Fuel Consumption

From the Fig-2 we can conclude that for low and medium loading condition fuel consumption for diesel fuel remains lower than biodiesel blends but at higher load fuel 
consumption for B20 blend was observed lower than diesel and other blends. Also it can be seen from the graph that at all loads fuel consumption for B20 blend is lowest in comparison to all other blends. Fuel consumption for B40 and $\mathrm{B} 50$ remains higher at all loading condition compare to others; this is due to decrease in calorific values comparatively at higher blends.Figure 3 shows the graph of comparison of brake thermal efficiency vs load for all tested fuel. we can see from the graph that engine gives higher brake thermal efficiency at higher loading condition for all fuels.

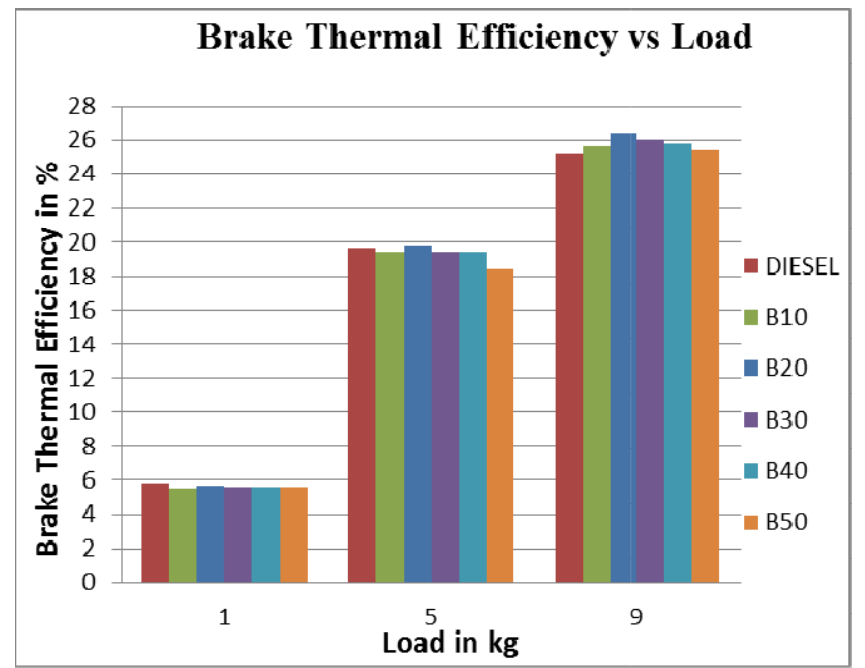

Fig-3. Comparison of Brake Thermal Efficiency

If we compare for all the fuel tested then at lower load brake thermal efficiency of all the fuels is almost same however to be accurate we can say that efficiency of diesel is marginally higher. But at medium load we can see that B20 fuel has higher efficiency $(19.82 \%)$ than all other fuel and diesel $(19.65 \%)$ remains at second position. At the higher load highest efficiency was found for B20 blend that is $26.42 \%$. Also one other thing we can observe from the Fig-3 is that thermal efficiency of other biodiesel blends found higher than the diesel fuel at this higher load condition and that might be due to better combustion process in the cylinder for biodiesel blends due to oxygen content in them.

As performance of jatropha biodiesel blend B20 was found comparatively higher for the all loading condition, complete energy analysis is shown in the Fig-4 and Fig-5 for biodiesel blend B20 and petroleum diesel respectively. In Fig-4 and Fig-5 various values from energy analysis is represented in percentage of input energy. For B20 and diesel fuel brake power is $26.42 \%$ and $25.19 \%$ respectively from the input energy. Sum of heat loss in engine cooling and exhaust gas is more than $50 \%$ for both B20 and diesel fuel that means more than $50 \%$ of energy input is get wasted in terms of heat energy into atmosphere hence this should be utilize.

\subsection{Emission Performance}

Emission from the engine was measured with the help of the exhaust gas analyzer. It can measure emission of $\mathrm{CO} 2$ and $\mathrm{CO}$ volume fraction basis and measure NOx and hydro carbon(HC) emission in parts per million(ppm). From the exhaust analysis it was observed that there was no significant difference observed for $\mathrm{CO} 2$ and $\mathrm{CO}$ and $\mathrm{HC}$ emission for biodiesel blends and diesel. So only NOx emission comparison is shown in Fig-6:

Form the Fig-6 we can conclude that as load increases NOx emission increases for all fuels. At low and mediumload NOx emission is almost similar for all biodiesel blends and diesel has lowest value among all. At high load diesel has lowest NOx emission among all fuel except B50 blend. Also it was observed that NOx emission is get lower as blend ratio increases.

\section{Diesel Energy Analysis}

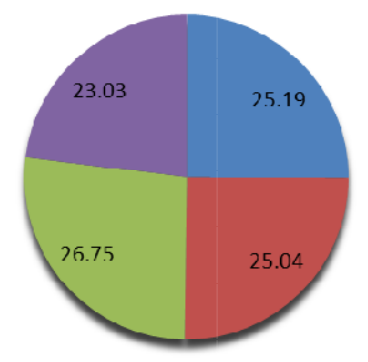

\%Qbp

\%Qcw

\%Qex

\%Qun

Fig-4. Diesel Fuel Complete Energy Analysis

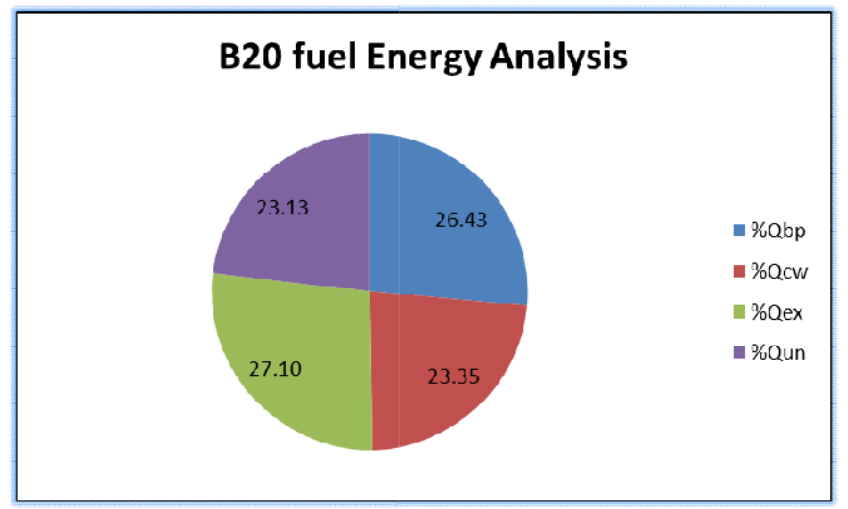

Fig-5. B20 Blend Complete Energy Analysis

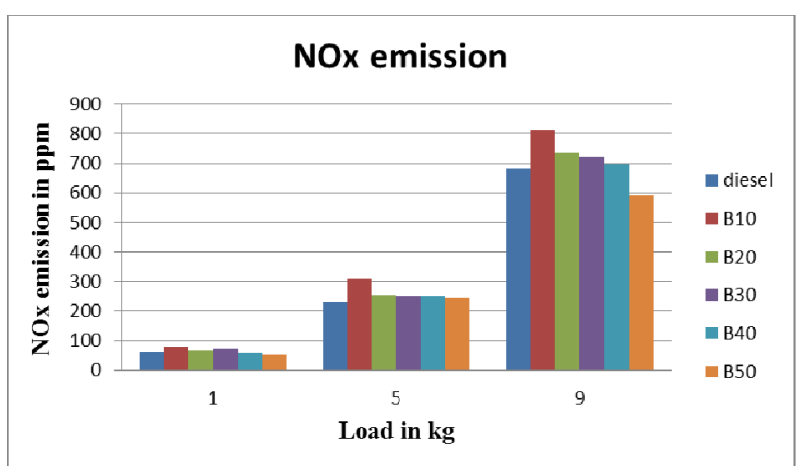

Fig-6. Nox emission for All fuel at all loads

\section{CONCLUSION}

From the energy analysis it can be concluded that brake thermal efficiency of the biodiesel blends tend to increase toward that of conventional diesel fuel as load increases from low to high. 
At the high load brake thermal efficiency of all the biodiesel blends is observed higher than the diesel so we can conclude that though biodiesel blends have lower calorific values than diesel; but improved combustion process and less exergy destruction or less irreversible process of combustion might be the reason for the higher performance than the diesel.

Fuel consumption of biodiesel blends are found comparatively higher than the diesel at all loading condition except B20 blend which shows almost similar values as that of diesel. Reason for the higher fuel consumption is their comparatively lower calorific value.

From the emission performance it can be concluded that biodiesel have similar kind of emission performance as that of diesel. CO emission was observed marginally lower for biodiesel and NOx emission is higher for biodiesel blends compare to diesel but as blend ratio increases NOx emission tend to get lower for blends(B10 to B50) at all loads.

So from this performance and emission analysis we can conclude that lower blend ratio of biodiesel can be successfully used for diesel engine without modification. Effect of operating parameter must be checked to optimize the performance for lower blends. For higher blend ratio fuel consumption is higher which may restrict the use of higher blends in engine. In this experiment B20 blend has comparatively higher performance than others.

\section{ACKNOWLEDGEMENT}

Author 1 would like to thank LDRP Institute of Technology and Research, Gandhinagar for allowing such research work in the laboratory. Also Author 1 is thankful to chemical laboratory testing owner Girish Sahasrabuddhe for help.

\section{Nomenclature}

LCV Lower Calorific Value $(\mathrm{kJ} / \mathrm{kg})$

$\dot{Q}$ Heat/Work Transfer Rate $(\mathrm{kW})$

$\mathrm{N}$ Speed (rpm)

$\mathrm{T} \quad$ Torque $(\mathrm{Nm})$

$\dot{m} \quad$ Mass flow rate $(\mathrm{kg} / \mathrm{sec})$

Cp Constant Pressure Specific Heat $(\mathrm{kJ} / \mathrm{kg} \mathrm{K})$

$\mathrm{T} \quad$ Temperature (K)

\section{Sub/Super Scripts}

f fuel

S shaft

cw cooling water

ex exhaust gas

aair

bp brake power

c engine or calorimeter water temperature subscript

\section{REFERENCES}

[1] Asharful AB, Masjuki HH, Kalam M, Fattah R, Sahir $\mathrm{S}$, Mobarak H. Production and comparison of fuel properties, engine performance, and emission characteristics of biodiesel from various nonedible vegetable oils : A review, (80)2014:202-28
[2] Sekmen P, Yilbasi Z. Application of energy and exergy analysis to a ci engine using biodiesel fuel, 2011; vol 16(4); 797-808

[3] Tat M, Cetane number effect on the energetic and exergetic efficiency of a diesel engine fuelled with biodiesel Elsevier 92(2011)1311-21

[4] Takase M, Zhao T, Zhang M, Chen Y, Liu H, Yang L, $\mathrm{Wu} \mathrm{X}$. An expatriate review of neem, jatropha, rubber and karanja as multipurpose non-edible biodiesel resources and comparison of their fuel, engine and emission properties, Elsevier 43(2015):495-520

[5] Panigrahi N, Mohanty M, Mishra S, Mohanty R. Performance, Emission, Energy, and Exergy Analysis of a C.I. Engine using Mahua Biodiesel Blends with Diesel, 2014; Hindawi, Paper ID 207465; 1-13

[6] Sivalakshmi S , Balusamy T. The performance, combustion and emission characteristics of neem oil methyl ester and its diesel blends in a diesel engine, 2013; ISSN 1576-7036 :pp142-49

[7] Jibanananda Jena, Rahul Dev Misra. Effect of fuel oxygen on the enegetic and exergetic efficiency of a compression ignition engine fuelled separately with palm and karanja biodiesels, 60(2014):411-19

[8] Agrawal D, Kumar L, Agrawal AK. Performance evaluation of vegetable oil fuelled compression ignition engine. Renewable Energy 33(2008):1147-56

[9] Ramdhas A S, Muraledharan C, Jayraj S. performance and emission evaluation of a diesel engine fuelled with methyl ester of rubber seed oil. Renewable energy 30(2005): 1789-1800

[10] Ganapaty T, Gakkhar R, Murugesan K. Influence of injection timing on performance, combustion and emission characteristics of Jatropha biodiesel engine, Elsevier 88(2011):4376-86.

[11] http://business.rediff.com/report/2010/apr/27/govtsbiofuel-dream-fails-to-take-off.htm

[12] Test Engine Manual

[13] A Course in Internal Combustion Engines by V M Domkundwar, Dhanpat Rai and Company publication, 2012 reprint edition 